\title{
Analysis of Tea pesticide residue standards and testing methods
}

\author{
Jing Chen ${ }^{1, a}$, Jia-ming Rui ${ }^{2, b}$ and Xiao-rong Liü ${ }^{1, c}$ \\ ${ }^{1}$ School of Beijing, Beijing Wuzi University, Beijing 101149, China; \\ 2 School of Beijing, Beijing Wuzi University, Beijing 101149, China.

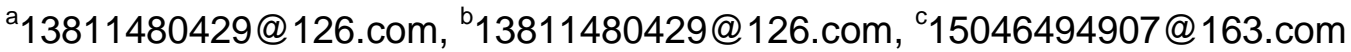

Keywords: tea, food safety, pesticide residue, standards, detection methods, control measures

\begin{abstract}
Tea has always been China's traditional agricultural crops, and is one of a large number of agricultural exports. However, in recent years, China's tea exports encountered the biggest problem is pesticide residues,developed countries or regions to limit pesticide residues in tea standards have hindered the development of China's tea exports.Aiming Situation to Analysis and Research of China's tea exports to China tea pesticide residue limits with the European Union, Japan, the United States and other developed countries or regions as well as the United Nations Food Codex Committee on Pesticide Residues (CODEX) differences tea pesticide residue limits exist, this article proposed more specific response.At the same time, through the analysis of pesticide residues in tea different methods and control measures, to improve the tea pesticide residue standards, source control, and improve tea security, we made recommendations to make China's tea product quality and international standards as soon as possible.
\end{abstract}

\section{Tea pesticide residue limit standard analytical research and response measures}

China is not only the country where people cultivate tea, process tea and export tea, but also is the first country to start growing tea.The growing of tea export trade has accelerated the production of tea quality and safety standards.In order to achieve purposes to control the quality and safety of tea, tea quality and safety indicators involved in the relevant standards are being tested, and the resulting detection limits and standards to make data comparison, the amount of pesticide residues in tea come whether there is or prohibited pesticides is exceeded.

The different principles of pesticide residue standards lead to the existence of some differences pesticide residue standards at home and abroad.Because of this difference, domestic and foreign generated considerable controversy about tea is excessive pesticide residues, but also it formed a resistance for China's tea exports.Lipton is the world's leading brand of tea why its production of quality products should meet the requirements.

Facts have proved that "double standards" of pesticide residues in tea has seriously hindered the development of China's tea exports,therefore, to enhance the importance of tea in standards and control methods pesticide residues and to be in line with international standards as much as possible are of great significance to enhance the quality of tea products. This can not only improve the status and influence of Chinese tea in the international community, but it is a guarantee of consumer safety. Foreign tea pesticide residue standards.There are more than 50 tea-producing countries and more than 130 tea-consuming countries all over the world. The international tea market is given priority to with black tea trade, accounting for more than $88 \%$ of total international tea trade. Therefore, foreign tea product quality standards are mainly black tea standard, namely tea mainly to international standards ISO 3720-1986 "tea - Definition and basic requirements" as the representative.

Pesticide residue standards of domestic tea.Our tea have wide variety and tea products are varied.Many departments have developed and released tea standards.China's current standards related to tea include international standards, tea export standards and domestic goods tea standards this 3 level.International standards have product standards and testing methods standard categories, such as ISO 6079-1990 "the solid instant tea specifications", IS0 7516- 1984 "solid instant tea sampling."The standard of exports tea is the foreign trade industry standards, namely commodity-importing countries 
to follow tea standard. The standard of commodity tea in China's domestic is more complicated.There are four levels: national standards, industry standards, local standards and enterprise standards.

This series of changes in standards, indicating that China's tea pesticide residue standards are working gradually into line with international standards.

Compare for pesticide residues. The following chart lists some comparisons of the United States, Japan, EU and China Standard:

Table 1

\begin{tabular}{|c|c|c|}
\hline \multicolumn{2}{|c|}{ CAC standard tea pesticide maximum residue limits } \\
\hline Chinese name & English name & Limit $(\mathrm{mg} / \mathrm{kg})$ \\
\hline 百草枯Paraquat 0.2 & Paraquat & 0.2 \\
\hline 甲硫咪唑 & Methidathion & 0.5 \\
\hline 噻虫胺 & Clothianidin & 0.7 \\
\hline 甲氧菊酯 & Fenpropathrin & 2 \\
\hline 陶斯松 & Chlorpyrifos & 2 \\
\hline 澳氧菊酯 & Deltamethrin & 5 \\
\hline 克螨特 & Propargite & 5 \\
\hline 硫丹 & Endosulfan & 10 \\
\hline 乙螨唑 & Etoxazole & 15 \\
\hline 氯氧菊酯 & Cypermethrins & 20 \\
\hline 芐氯菊酯 & Permethrin & 20 \\
\hline 噻虫嗪 & Thiamethoxam & 20 \\
\hline 联苯菊酯 & Bifenthrin & 30 \\
\hline 三氯杀螨醇 & Dicofol & 50 \\
\hline
\end{tabular}

Table 2

\begin{tabular}{|c|c|c|c|c|}
\hline \multicolumn{5}{|c|}{ Our pesticide limit compared with the EU requirements, the Japanese standard } \\
\hline Chinese name & English name & $\begin{array}{c}\text { China } \\
\text { Limited }(\mathrm{mg} / \mathrm{kg})\end{array}$ & $\begin{array}{c}\text { Japan } \\
\text { Limited }(\mathrm{mg} / \mathrm{kg})\end{array}$ & EU Limited $(\mathrm{mg} / \mathrm{kg})$ \\
\hline 苯醚甲环唑 & Difenoconazole & 10 & 10 & 0.05 \\
\hline 吡虫啉 & Imidacloprid & 0.5 & 10 & 0.05 \\
\hline 草铵膦 & $\begin{array}{l}\text { Glufosinate- } \\
\text { ammonium }\end{array}$ & $0.5 *$ & 0.01 & 0.1 \\
\hline 草甘膦 & Glyphosate & 1 & 1 & 2 \\
\hline 除虫嫝 & Diflubenzuron & 20 & 20 & 0.1 \\
\hline 哒螨灵 & Pyridaben & 5 & 10 & 0.05 \\
\hline 丁醚脲 & Diafenthiuron & $5 *$ & 20 & 0.01 \\
\hline 多菌灵 & Carbendazim & 5 & 10 & 0.1 \\
\hline 氟氯氰菊酯 & Cyfluthrin & 1 & 20 & 0.1 \\
\hline 氟氰戊菊酯 & Flucythrinate & 20 & 20 & 0.1 \\
\hline 甲氰菊酯 & Fenpropathrin & 5 & 25 & 2 \\
\hline 联苯菊酯 & Bifenthrin & 5 & 25 & 5 \\
\hline 硫丹 & Endosulfan & $10 *$ & 30 & 30 \\
\hline 氯氟氰菊酯 & Cyhalothrin & 15 & 0.01 & 1 \\
\hline 氯菊酯 & Permethrin & 20 & 20 & 0.1 \\
\hline 氯氰菊酯 & Cypermethrin & 20 & 20 & 0.5 \\
\hline 灭多威 & Methomy 1 & 3 & 0.01 & 0.1 \\
\hline 噻虫嗪 & Thiamethoxam & 10 & 15 & 0.1 \\
\hline 噻嗪酮 & Buprofezin & 10 & 20 & 0.05 \\
\hline 杀螟丹 & Cartap & 20 & 30 & 0.1 \\
\hline 杀蛽硫磷 & Fenitrothion & $0.5 *$ & 0.2 & 0.5 \\
\hline 溴氧菊酯 & Deltamethrin & 10 & 10 & 5 \\
\hline 乙酰甲胺磷 & Acephate & 0.1 & 10 & 0.05 \\
\hline 滴滴涕 & DDT & 0.2 & 0.2 & 0.2 \\
\hline
\end{tabular}




\begin{tabular}{|c|c|c|c|c|}
\hline 六六六 & $\mathrm{HCB}$ & 0.2 & 0.2 & 0.02 \\
\hline
\end{tabular}

Note: "*" indicates a temporary limit

Table 2 shows the 25 indicators of maximum levels of pesticide residues in tea in the new standard of March 1, 2013 implementation date.The following is Chinese tea pesticide residue limits in comparison with American,Japan and European.

By comparing Tables 1 and 2, you can see that China's tea pesticide residue standards: thiamethoxam, Fenpropathrin, bifenthrin, permethrin, endosulfan, cypermethrin, deltamethrin seven kinds of pesticides CAC required in pesticide maximum residue limits of standard.Only confirmed intake of a pesticide residue exceeding a certain amount will cause some harm to the human body when, CAC standards for pesticide residues will be included in the standard.

\section{Research the causes of pesticide residues in tea and detection methods}

Analysis of pesticide residue in tea Status.Throughout China's tea pesticide residues in the history found that BHC and DDT pesticide was based 90 years ago.State Department specifically prohibit the use of DDT and BHC in tea early in 1972 on fruits and vegetables and other agricultural products.But because farmers over-reliance on pesticides and the surrounding crops also have the use of two highly toxic, high pesticide residues, so pesticide content, although the decline but still exists.But because farmers over-reliance on pesticides and the surrounding crops also have the use of two highly toxic, high pesticide residues, so pesticide content, although the decline but still exists.Until 1983 our government promulgated standards prohibit the production and use of BHC and DDT, which was banned two pesticides sprayed directly on the tea act.Since 1984, pesticide hierarchy began to implement in our country.

In recent years, the international community has detected excessive pesticide gifted musicians too, fenvalerate in China's exports of tea and other products.And because in recent years the international standards for pesticide residue limits become more stringent, which the European Union the most demanding, whether it is the type of pesticide residues in or on its limited, are far stricter than our existing standards, resulting in the export country process tea in repeatedly rebuffed, has formed a technical trade barriers.

Causes of pesticide residues in tea. Since the cultivation of tea in the park much more remote mountainous areas, farmers have not been scientific, effective education on how to reduce the tea pests and diseases know no advanced scientific methods, coupled with the consequences of excessive use of pesticides is not consciousness, leading in the process of planting misuse of pesticides.

A. Tea main way of pesticide residues. The main pathway of pesticide residues in tea, there are two:1) direct spray.Directly spraying pesticides on tea, there will be a part of pesticides in foliar surface and still some deep through the skin to the internal organization of tea. After the role of time, light and other in multiple factors, the gradual transition to non-toxic. 2)Indirect access. There are three ways to obtain pesticide on Indirect way: One is the absorption resulting from soil.Another one is Obtained from the water.The rest is Air drift.

B. Lax government supervision. Although China since 1983 had banned the production or use of $\mathrm{HCH}$ and DDT such toxic pesticides, but some farmers in order to achieve resist pests diseases, increase tea production and other purposes, still use this and other pesticides, resulting in tea excessive pesticide residues, seriously affected the export of tea.

C. Standard did not timely promotion.Farmers have not been learning science, systems for hazardous pesticide use and there is a certain blindness. Although implemented new and more stringent standards, because the promotion is not in place, farmers do not really understand the new standards and clearly. And the absence of effective governance approaches, so farmers rely on pesticides for disease infestation of science to maintain high output of tea, but it does at the expense of the reputation of the quality of tea and Chinese tea for the price. 
Since Our country is a big country's tea exports, but because there is no scientific cultivation methods, strict management tools and chaos, inadequate standards and other reasons, our product quality and reputation of the tea has not improved. Faced with more stringent international quality standards and more advanced means of detection, only positive action to change the status quo of China's tea is now facing, in order to make tea exports out of the woods, re-establish the brand and reputation in the international arena.

First,Standards are the basis for everything, only to establish a unified and perfect system of quality and safety, in order to further the implementation process.For existing standards, to speed up the integration, improve the speed of standard system tends to improve as soon as possible, to avoid duplication, the cross, the requirements of national and local indicators, industry and corporate standards are not uniform among the problems. Similarly, with more perfect quality management system, and ultimately correct, strict management tools. New standards in a timely manner to promote and popularize, has banned the use of pesticides should be strictly regulated.

Second,Strengthen pesticide residues means of detection capability that can monitor both the quality and safety of tea does not produce tea, but off in the production process, the foundation also established a new standard.Compared to Japan where the same species as the more than 80 kinds of pesticides in tea producing countries, but Japan limits on pesticide residues in tea indicators higher targeted, but China did not have a complete laboratory can detect use in tea .

Third,accelerating the development of alternatives to pesticide speed, or using of organic fertilizers alternatives to pesticides, or reducing misuse of pesticides from tea cultivation process are also an effective means to reduce pesticide residues in tea.

\section{References}

[1] Yue-xin-min-te. EU pesticide residues in tea new standards seriously affect my tea export[N]. International Trade News.(2000).in Chinese.

[2] Yu-liang Haung. Establishment and application of pesticide residues in tea detection method[D]. Fujian Agriculture and Forestry University.(2012).in Chinese.

[3] Ai-min Cao. Measures to reduce pesticide residues in tea and Countermeasures[J]. Beijing Agriculture.(2011).in Chinese.

[4] Jiang-lie Ye, Gui-e Jin, Wan-e Zhuang, Wen-hui Zheng, Yun-hui Wu. Dispersive solid phase extraction GC- $\mu$ ECD Tea by 20 kinds of pesticide residues[J]. Analysis Laboratory.(2011).in Chinese.

[5] Zhi-guo Shan, Chun-hua Zhang, Nai-ming Zhang. Progress tea pesticide residues and manner of degradation[J]. Simao Teachers College.(2011).in Chinese.

[6] Bei-zhen Hu, Guo-jun Shen, Tie-feng Shao, Li-ping Xie. Accelerated solvent extraction - gas chromatography - negative chemical ionization mass spectrometry organochlorine and pyrethroid pesticide residues in tea[J]. Analysis Laboratory. (2009).in Chinese.

[7] Xiao-lin Tong, Wei Zhou. EU new standards for pesticide residues in tea Analysis and Countermeasures[J]. Inspection and Quarantine Science.(2005).in Chinese.

[8] Shan-ting Ying, Ning Li, Han-jun Yao, Guo-kun Dong, Cai-xia Sun, Qiang-hua Zhang. How to deal with the new EU standards in tea export tea pesticide residues[J]. Tea Bulletin.(2009).in Chinese.

[9] Yu Sun. Situation Analysis of Chinese tea exports[J]. Tea World.(2010).in Chinese.

[10] He-li Zhang, You-qin Shu. Tea pesticide residue detection method Overview[J]. Hubei Agricultural Sciences.(2010).in Chinese.

[11] Mei Han, Sheng-guo Yi, Ding-qing Yang, Xue Hou, Xiao-feng Yang, Xiao-mei Luo. A routine tea pesticide residues detected by gas chromatography[J]. Southwest China Journal of Agricultural Sciences.(2010).in Chinese. 